\title{
Noninvasive imaging of pediatric pancreatitis: joint recommendations from the North American Society for Pediatric Gastroenterology, Hepatology and Nutrition and the Society for Pediatric Radiology
}

\author{
Andrew T. Trout ${ }^{1,2,3}$ (D) S Sudha A. Anupindi ${ }^{4}$ - Sohail Z. Husain ${ }^{5} \cdot$ Veronique D. Morinville $^{6} \cdot$ Maisam Abu-El-Haija $^{3,7}$
}

Received: 13 April 2020 / Revised: 13 April 2020 / Accepted: 11 August 2020 / Published online: 15 October 2020

(C) Springer-Verlag GmbH Germany, part of Springer Nature 2020

In a recent article in Journal of Pediatric Gastroenterology and Nutrition, members of the Society for Pediatric Radiology (SPR) Abdominal Imaging Committee and the Pancreas Committee under the umbrella of the North American Society for Pediatric Gastroenterology, Hepatology \& Nutrition (NASPGHAN) published joint recommendations for noninvasive imaging of pancreatitis in children [1]. The project, titled "NASPGHAN and the Society for Pediatric Radiology Joint Position Paper on Non-Invasive Imaging of Pediatric Pancreatitis: Literature Summary and Recommendations,"

Andrew T. Trout

andrew.trout@cchmc.org

1 Department of Radiology,

Cincinnati Children's Hospital Medical Center,

3333 Burnet Ave., MLC 5031, Cincinnati, OH 45229-3026, USA

2 Department of Radiology,

University of Cincinnati College of Medicine,

Cincinnati, OH, USA

3 Department of Pediatrics,

University of Cincinnati College of Medicine,

Cincinnati, OH, USA

4 Department of Radiology, The Children's Hospital of Philadelphia, University of Pennsylvania Perelman School of Medicine, Philadelphia, PA, USA

5 Division of Gastroenterology, Hepatology, and Nutrition, Department of Pediatrics, Stanford School of Medicine, Stanford, CA, USA

6 Department of Pediatrics, Montreal Children's Hospital, McGill University, Montreal, Quebec, Canada

7 Division of Gastroenterology, Hepatology and Nutrition, Cincinnati Children's Hospital Medical Center, Cincinnati, OH, USA grew out of a perceived need for current guidance for pediatric gastroenterologists on imaging of pancreatitis and capitalized on collaboration between the two societies.

The incidence of pancreatitis is increasing in children and is now approximately $1: 10,000$ for acute pancreatitis and $2: 100,000$ for chronic pancreatitis [2-4]. Imaging plays a substantial role in the evaluation, classification of severity and management of both acute and chronic pancreatitis [5]. In this work, the authors reviewed the existing pediatric literature and drew from the adult literature when necessary to describe the current state of noninvasive imaging for pediatric pancreatitis and to generate consensus recommendations (Table 1) [6]. A modified GRADE (grades of recommendation assessment, development and evaluation) procedure that weighs the quality of available evidence and the clarity of risk/benefit was used to classify the recommendations put forth.

Specific diagnostic criteria exist for both acute and chronic pancreatitis, and both include imaging findings [7]. Imaging contributes not only to making or confirming a diagnosis (when needed), but also to identifying and characterizing complications, identifying potential causes, and planning and guiding interventions [5]. Ultrasonography (US) CT and MRI all play roles in the noninvasive imaging of pediatric pancreatitis and the authors discussed the strengths, weaknesses and diagnostic performance of each, providing protocol and technique recommendations.

Specific imaging findings of acute and chronic pancreatitis are reviewed with emphasis on the performance of various imaging modalities to detect and characterize those findings. For example, in acute pancreatitis, CT might underestimate the complexity of fluid collections compared to US or MRI. Further, the authors emphasized the use of currently accepted terminology when describing findings of pancreatitis. For example, in the context of acute pancreatitis, accurately 
Table 1 Summary statements and recommendations

\begin{tabular}{|c|c|c|c|c|}
\hline $\begin{array}{l}\text { Statement } \\
\text { number }\end{array}$ & Statement/recommendation & $\begin{array}{l}\text { Grade } \\
{[6]}\end{array}$ & Agreement $^{\mathrm{a}}$ & $\begin{array}{l}\text { Average } \\
\text { score }\end{array}$ \\
\hline \multicolumn{5}{|c|}{ General imaging } \\
\hline 1 & $\begin{array}{l}\text { CT should be performed with intravenous contrast material } \\
\text { as a single portal venous phase exam unless specific } \\
\text { arterial detail is needed }\end{array}$ & $1 \mathrm{C}$ & $\begin{array}{l}100 \% \\
(11 / 11)\end{array}$ & 4.5 \\
\hline 2 & $\begin{array}{l}\text { When imaging with MRI, intravenous contrast material is } \\
\text { not always needed but contributes to the diagnosis and } \\
\text { definition of necrosis, assessment of the vasculature and } \\
\text { the diagnosis of autoimmune pancreatitis }\end{array}$ & $2 \mathrm{C}$ & $\begin{array}{l}100 \% \\
(11 / 11)\end{array}$ & 4.3 \\
\hline \multicolumn{5}{|c|}{ Acute pancreatitis } \\
\hline 3 & $\begin{array}{l}\text { Transabdominal ultrasound is recommended as } \\
\text { a first-line noninvasive imaging modality for suspected } \\
\text { acute pancreatitis }\end{array}$ & $1 \mathrm{~B}$ & $\begin{array}{l}91 \% \\
(10 / 11)\end{array}$ & 4.7 \\
\hline 4 & $\begin{array}{l}\text { If ultrasound is negative for acute pancreatitis and an } \\
\text { imaging diagnosis of acute pancreatitis is needed, either } \\
\text { CT or MRI is recommended }\end{array}$ & $1 \mathrm{~B}$ & $\begin{array}{l}100 \% \\
(11 / 11)\end{array}$ & 4.6 \\
\hline 5 & $\begin{array}{l}\text { CT or MRI is recommended for identification and } \\
\text { assessment of known or suspected complications of } \\
\text { acute pancreatitis }\end{array}$ & $1 \mathrm{C}$ & $\begin{array}{l}91 \% \\
(10 / 11)\end{array}$ & 4.5 \\
\hline 6 & $\begin{array}{l}\text { Ultrasound can be used to follow known acute pancreatitis } \\
\text { fluid collections for resolution or progression } \\
\text { (changes in size) }\end{array}$ & $2 \mathrm{C}$ & $\begin{array}{l}82 \% \\
(9 / 11)\end{array}$ & 4.3 \\
\hline 7 & $\begin{array}{l}\text { CT or MRI should be used to characterize the degree of } \\
\text { organization of collections prior to intervention }\end{array}$ & $1 \mathrm{C}$ & $\begin{array}{l}100 \% \\
(11 / 11)\end{array}$ & 4.5 \\
\hline \multicolumn{5}{|c|}{ Acute recurrent pancreatitis } \\
\hline 8 & $\begin{array}{l}\text { MRI is recommended to identify structural or obstructive } \\
\text { causes for acute recurrent pancreatitis }\end{array}$ & 1B & $\begin{array}{l}100 \% \\
(11 / 11)\end{array}$ & 4.8 \\
\hline 9 & $\begin{array}{l}\text { When clinically indicated, MRI is recommended to follow } \\
\text { children with acute recurrent pancreatitis and to assess } \\
\text { for progression to chronic pancreatitis }\end{array}$ & $1 \mathrm{C}$ & $\begin{array}{l}100 \% \\
(11 / 11)\end{array}$ & 4.6 \\
\hline 10 & $\begin{array}{l}\text { In a child who requires sedation for imaging, it is } \\
\text { reasonable to alternate MRI with ultrasound or CT for } \\
\text { serial monitoring of acute recurrent pancreatitis }\end{array}$ & $2 \mathrm{C}$ & $\begin{array}{l}82 \% \\
(9 / 11)\end{array}$ & 4.0 \\
\hline \multicolumn{5}{|c|}{ Chronic pancreatitis } \\
\hline 11 & $\begin{array}{l}\text { MRI is the recommended modality for imaging of } \\
\text { suspected chronic pancreatitis }\end{array}$ & $1 \mathrm{C}$ & $\begin{array}{l}91 \% \\
(10 / 11)\end{array}$ & 4.6 \\
\hline 12 & $\begin{array}{l}\text { When imaging is needed to assess a suspected or known } \\
\text { episode of acute pancreatitis in a child with chronic } \\
\text { pancreatitis, transabdominal ultrasound is the preferred } \\
\text { first-line imaging modality }\end{array}$ & $1 \mathrm{~B}$ & $\begin{array}{l}91 \% \\
(10 / 11)\end{array}$ & 4.5 \\
\hline 13 & $\begin{array}{l}\text { If ultrasound is negative for acute pancreatitis in a child } \\
\text { with chronic pancreatitis and an imaging diagnosis of } \\
\text { acute pancreatitis is needed, either CT or MRI } \\
\text { is recommended }\end{array}$ & $1 \mathrm{~B}$ & $\begin{array}{l}100 \% \\
(11 / 11)\end{array}$ & 4.5 \\
\hline 14 & $\begin{array}{l}\mathrm{CT} \text { or MRI is recommended for planning of endoscopic } \\
\text { or surgical interventions in a child with known } \\
\text { chronic pancreatitis }\end{array}$ & $2 \mathrm{C}$ & $\begin{array}{l}100 \% \\
(11 / 11)\end{array}$ & 4.5 \\
\hline 15 & $\begin{array}{l}\text { MRI is recommended for clinically indicated serial } \\
\text { imaging of chronic pancreatitis }\end{array}$ & $1 \mathrm{~B}$ & $\begin{array}{l}100 \% \\
(11 / 11)\end{array}$ & 4.8 \\
\hline
\end{tabular}

Reproduced with permission [1]

${ }^{a}$ Agreement denotes frequency of strongly agree and agree votes describing findings of necrosis or acute fluid or necrotic collections impacts classification of disease severity and sometimes has management implications.

Emerging techniques such as MRI T1 mapping, elastography and secretin-enhanced magnetic resonance cholangiopancreatography are discussed, particularly with regard to the growing emphasis on quantitative measures of disease.

The authors also called out areas of necessary future research, highlighting significant gaps in the pediatric literature. Specifically, the authors called out the need to define the optimal imaging strategy (and modalities) for all forms of 
pediatric pancreatitis. They also expressed the need for research to identify imaging that can prognosticate and predict pancreatitis severity and progression, contributing to clinical care and acting as outcome and stratification measures for clinical trials. Finally, they called out the significant need for research to identify modalities that can diagnose minimal change disease, the very earliest form of chronic pancreatitis, which might reflect an opportunity to intervene and prevent disease progression or reduce patient morbidity.

The published position paper and its recommendations have been endorsed by both the SPR and NASPGHAN. The target audience of this document is primarily pediatric gastroenterologists, but pediatric radiologists should also find the content informative, particularly the discussion of diagnostic criteria and protocol recommendations. There are significant opportunities for the pediatric radiology community to contribute to future research related to pediatric pancreatitis.

Acknowledgments The authors acknowledge the other contributing members of the writing group for this position paper: Jorge AlbertoMacias-Flores, MD; A. Jay Freeman, MD, MSc; J. Andres Martinez, MD; Kalyan Parashette, MD, MPH; Uzma Shah, MD; and Judy H. Squires, MD.

\section{Compliance with ethical standards}

Conflicts of interest Dr. Trout has received funding from Canon Medical Systems and in-kind research support from ChiRho Clin, Inc. Dr. Husain owns equity in Prevcon.

\section{References}

1. Trout AT, Anupindi SA, Freeman AJ et al (2020) NASPGHAN and the Society for Pediatric Radiology joint position paper on noninvasive imaging of pediatric pancreatitis: literature summary and recommendations. J Pediatr Gastroenterol Nutr. https://doi.org/10. 1097/MPG.0000000000002964

2. Hornung L, Szabo FK, Kalkwarf HJ et al (2017) Increased burden of pediatric acute pancreatitis on the health care system. Pancreas 46: $1111-1114$

3. Hornung LN, Szabo FK, Kalkwarf HJ et al (2018) Stabilized incidence of pediatric acute pancreatitis. Pancreas 47:e60-e62

4. Sellers ZM, MacIsaac D, Yu H et al (2018) Nationwide trends in acute and chronic pancreatitis among privately insured children and non-elderly adults in the United States, 2007-2014. Gastroenterology 155:469-478

5. Abu-El-Haija M, Kumar S, Szabo F et al (2017) Classification of acute pancreatitis in the pediatric population: clinical report from the NASPGHAN pancreas committee. J Pediatr Gastroenterol Nutr 64: 984-990

6. Shekelle P, Aronson MD, Givens J (2020) Overview of clinical practice guidelines. UpToDate. https://www.uptodate.com/ contents/overview-of-clinical-practice-guidelines. Accessed 21 April 2020

7. Morinville VD, Husain SZ, Bai $\mathrm{H}$ et al (2012) Definitions of pediatric pancreatitis and survey of present clinical practices. J Pediatr Gastroenterol Nutr 55:261-265

Publisher's note Springer Nature remains neutral with regard to jurisdictional claims in published maps and institutional affiliations. 